\title{
Etnografik Filmden Sosyal Bilimlere: Bir Bilgi Formu Olarak Görsellik
}

\author{
Gülsüm Depeli
}

\begin{abstract}
Öz
Bu çalışma, insanların imgeler ile kuşatıldığı bir dönemde, görsel içeriklerin sadece bilgi ve analiz nesnesi değil, bilgi formu olarak da yeniden değerlendirilmesi gerektiği düşüncesiyle gerçekleştirilmiştir. Bu doğrultuda, üç temel bölüm olarak yapılanmış metinde, önce göz, bakış ve imge ile ilgili kısa bir kuramsal çerçeve sunulmakta, devamında etnografik filmler ile antropoloji disiplini arasında yaşanan "bilimsellik" tartışmaları özetlenmektedir. Bu tartışmalar, sosyal bilimler içinde görsel metinlerin yerini sorgulamaya başlamak açısından önemli bir hareket noktası sunabilecek niteliktedir. Zira etnografik film deneyimi etrafında özellikle bilgi ve yöntembilim çerçevesinde başlayan sorgulamaların ürettiği kavramlar seti ve temalar günümüzde tüm sosyal bilimler için geçerliliğini korumaktadır. Bu tartışmalar yeni imge teknolojileri ve imge rejimleri doğrultusunda zenginleştirilmelidir.
\end{abstract}

Anahtar Kelimeler: Etnografik Film, Antropoloji, Yöntembilim, Görsellik, Bilgi Formu.

\section{From Ethnographic Films to Social Sciences: Visuality as a Form of Knowledge}

\begin{abstract}
This paper is written to assert that the visual contents (all kind of images) are not merely analyse objects to produce knowledge. On the contrary, they are subjects of knowledge; so, they offer distinct forms of knowledge. In this context, this article, focused on the controversary discussions on the scientific competency of images, is composed of three main sections. First, a theoretical discussion on eye, gaze and images is conducted. Afterwards, the contestation between anthropology and the ethnographic filmmakers about the "scientific validity" of visual texts is conveyed in brief. It is claimed that, these fevered discussions between the two components; i.e. anthopology and ethnographic film, have the potential to offer a productive starting point in order to begin a contemplation on the place of visual texts in the process of knowledge production. As a result, the main concepts and themes on methodology, which are first subjected in these discussions on ethnographic films, haven't lost anything from their actuality; on the contrary, they gained more importance in recent studies. Discussions on the relation between visuality and knowledge should be enriched through the experience of new image technologies and image regimes.
\end{abstract}

Keywords: Ethnographic Film, Anthropology, Methodology, Visuality, Form of Knowledge.

1 Yrd. Doç. Dr., Hacettepe Üniversitesi Illetişim Fakültesi. 


\section{Giriș}

$\mathrm{B}$ u çalışmada, antropoloji disiplininin görsel materyal ile olan ilişkisi ve etnografik film etrafındaki yöntembilimsel tartışmalar konu edilmektedir. Etnografik filmlerden yola çıkarak görsel materyalin bilimselliği konusundaki sorgulamalara odaklanan bu araştırmanın amacı, kültür ve iletişim bağlamında, görsellik ile sosyal bilimler arasında, gelişmeye açık bir bağlantı noktası tarif edebilmektir. Bu doğrultuda, alanda yapılan yöntembilimsel tartışmaların izini süren çalışmada, görselliğin sosyal bilimler alanında "bilgi formu" olarak nasıl değerlendirildiği sorgulanacaktır.

Etnografik filmler ile yöntembilimi ilişkilendiren literatürü değerlendirmek şu nedenle önemlidir: Antropoloji ve etnografik film deneyiminden yola çıkmakla birlikte bugün görsel çalışmaların, iletişim bilimleri, sosyoloji, güzel sanatlar vb. birçok yeni sosyal bilim bileşenine dâhil olduğu izlenebilmektedir. Yeni iletişim teknolojileriyle birlikte artık imge üretme ve paylaşma olanakları çoğullaşmış, bu yeni bir bilme durumunu somutlar hale gelmiştir. Mitchell'in (1995) "imgesel dönemeç" (pictorial turn)² kavramlaştırması ile yorumladığı, Mirzoeff'in (2002) ise "görsel kültür" olarak çerçevelediği günümüzde, iletişimin önemli ölçüde imgeselleştiği bir dönemde olduğunu söylemek mümkün. Bununla birlikte sosyal bilimler görsel kayıt kullanma ve görsel bilgi üretmenin anlamı üzerine düşünmek konusunda yöntembilimsel kararsızlığını hala sürdürmektedir. Oysaki görsel düşünce üzerine detaylı düşünmek bugün çok daha önemli ve gereklidir.

Sosyoloji, antropoloji, biyoloji ve hatta uzay çalışmalarına bakıldığında, bilimsel çalışmaların görsel içerik üretme ve kullanma pratiğine bütünüyle yabancı olmadığı ortadadır. Görsel teknolojinin sağladığı olanaklar (film, fotoğraf, mikroskop, teleskop, grafik düzenlemeleri olanaklı kılan bilgisayar programları vs.) bilimsel yöntemlere yeni araştırma araçları önerebilmekte, imgeler aracılığıyla da bilgi aktarılmasına ve hatta paylaşımasına olanak sunmaktadır. Buna bağlı olarak, teknik yeniliklerle birlikte, üretilen ve tüketilen bilginin niteliği de içerik ve biçimsel açıdan değişmektedir. Görsellik genel başlığında yapılan ilk literatür araştırmasında, konunun sanat (fotoğraf, resim, sinema, sanal tasarımlar, grafikler), felsefe (gözmerkezcilik, logosentrizm), antropoloji (kinesix, proxemics, gesture, paralanguage), sosyoloji (imge olarak sosyal tipler) ve hatta fen bilimleri alanlarının her birinde ayrı ayrı yer bulan, çok geniş bir alana yayıldığı gözlenmiştir. Bu çalışma ağırlıkla görselliğin antropoloji literatürü içinde nasıl yer aldığıüzerine yoğunlaşacaktır.

Görsel kaynaklar ve sosyal bilimlerin bağlantısını sorgulamada hareket noktası olarak antropoloji alanındaki tartışmaları seçmenin en önemli nedenlerden biri, "etnografik film" deneyiminin antropoloji tarihi içinde özel bir yer tutuyor olmasıdır. Bu deneyim, görsel içeriklerin sosyal bilimler ile ilişkisini kurmak açısından hatırlanmalı ve akademik bir soruya dönüşmelidir. Zira antropoloji, görselliğin bilimselliğine dair sürdürdüğü tartışmalarla hem sosyal bilimlerde görsellik üretimi ve kullanımını sorguya açmakta hem de yöntembilimin sınırlarını genişletmektedir. Bu doğrultuda çalışma hiç eskimeyen fakat yeterli ölçüde de cevaplanmamış olan bir sorunun peşinden gidecektir: Sosyal bilimlerde, görsel materyal kullanmanın mevcut örnekleri ve potansiyel olanakları nelerdir? Bu soru, dijital görsel kayıt olanaklarının gittikçe arttığı ve alan çalışmalarının kaçınılmaz bir bileşenine dönüştüğü, imgelerle ilişki kurmanın hem nicel hem de nitel olarak

2 Mitchell'in 1990'ların başında kullandığı resimsel/imgesel dönemeç kavramı, özellikle logosantrik ve dil merkezli düşünüm ile karakterize olan sosyal bilimlerin içeriğinde imgesel olanın yeniden görünürleştiğine ve bilgi ve anlam üretim mekanizmalarında önem kazandığına işaret eder. Zira pozitivist paradigmanın açıklama modellerinin çökmeye başladığı 1960 sonrasından itibaren yöntembilim içinde imgenin yeri sorgulanır olmuştur. Örneğin Erwin Panofsky (2012: 25 - 59).bilgi formu olarak imgenin ne olduğu ve nasıl analiz edilmesi gerektiği konusunda üç aşamalı "ikonolojik analiz"i geliştirmiştir. 
yoğunlaşı̆̆ı günümüzde özellikle önem kazanmaktadır.

Bu çalışmanın odağı etnografik filmler etrafında ortaya çıkan yöntembilimsel tartışmalar olarak belirlenmiştir. Fakat daha önce görselliğin göz, bakış ve imge bağlamlarındaki tarihsel serüveni üzerine kısa bir kuramsal çerçeve sunulacaktır.

\section{Göz, Bakıș, İmge: Kuramsal Bir Giriș}

Görsel kaynakların bilgi formu olarak nasıl algılandığını tarihsel bir bakışla, farklı dönemlere göre ayrıştırarak (antik, ortaçağ, Reform ve Rönesans, sanayi ve modern dönem) inceleyen Jay (1994), kuramsal perspektifini genelde Batı, özelde ise Fransız entelektüellerinin düşünceleri üzerinden kurmuştur. Jay (1994), gözün biyolojik niteliklerini, algıdaki konumunu ve göz etrafında yapılmış olan felsefi tartışmaları birleştiren, zengin, aynı zamanda bir o kadar da karmaşık bir kavram alanına girmiştir. Görselliğin özellikle etki ve içerim olarak, Antik Yunan'daki, farklı dinler alanındaki mevcudiyetini, gözün ve imgenin Reform döneminde uğradığı dinsel saldırıları, Rönesans döneminde ise artan itibarını örneklemiştir. Grimshaw (2001: 5), bakışa karşı duyulan şüphe ve endişe duygularını, Reform döneminde, resimlere yönelen saldırılarla örneklemektedir. Grimshaw'a göre (2001), özellikle görsel desenler ve resimler ile onları gören/izleyen arasındaki göz temasından ürkülmüş, resimdeki suretlerin gözleri oyulmuştur. Gözden korkmak için sebepler vardır; nitekim Jay de (1994: 3), gözün teknoloji yoluyla geliştirilmesinin (teleskop, mikroskop, fotoğraf, sinema), bilimsel, bir anlamda masum çabalarla değil, daha ziyade gözetleme ve gösteri ile ilişkilendirilmiş olduğuna işaret eder. Dinsel bağlamda bakışa olumsuz bir güç atfetme, göz ile ilgili teknolojik gelişmelerin yeni olanaklarını, "kötü göz"ün (evil eye) yayılması olarak değerlendirme, antropoloji ve sosyolojinin imgelere dönük bakışında da etkili olmuştur.

Görme kapasitesine yönelik güvensizlik ve görme etkinliğinin öznelliği ve yanılabilirliği bilimsel açıdan bakışa ve imgeye yönelik şüphe uyandırmıştır. ${ }^{3}$ Masumiyeti sorgulanan ve yetkinliği reddedilen, tecavüzkâr, şaşalı ve aldatıcı bulunan göz, pozitivist kestirim ve ölçülebilirlik kriterlerine uymamaktadır; bilimsel etkinliklerin ağırlığına ve prestijine zarar veren içerimi nedeniyle, dışarıda bırakılmalıdır (Grimshaw, 2001: 5). Jay (2004), bilimin disiplinerleşmeye başladığı 19. yüzyılın sonundan itibaren gözmerkezli (ocularcentric) yaklaşımların logosentrik ${ }^{4}$ yaklaşımların dominasyonu altına girdiği ve itibarını yitirdiğini ifade eder (Jay, 1994). Görsel içerik artık bilgi formu olmaktan ziyade gözlemin nesnesi haline gelmiştir. Hatta göz ve görmek konusu artık basitçe optiğe indirgenecek kadar pozitivize olmuştur (Crary, 2004: 83-84).

Öte yandan, ruhun aynası, dünyaya bakan pencere gibi metaforlarla gücü teslim edilen gözün ve görünürlük denen olgunun, bu denli basit bir hamleyle bilimsel çalışmaların dışına itilmesi pek yerinde bir sonuç olarak görünmemektedir. Zira "bir şeyi içsel olarak görselleştirme yeteneği, onu sözlü olarak betimleme yeteneğiyle çok yakından ilişkilidir. Sözlü ve yazılı betimlemeler yüksek derecede özel zihinsel imajlardır. (...) Görüş (vision), görsel hafıza ve sözelleştirme (verbalization) arasındaki bağlantı gerçekten şaşırtıcıdır” (Jay, 1994: 8-9).

Dolayısıyla, Aydınlanma'nın logosentrik yapısı tarafından içerilmese de, göz mevcudiyetini, dildeki

3 Gözün görme kapasitesinin düşük olduğu ve kusurlu gördüğü ile ilgili Descartes örnekler aktarmıştır. Örneğin, göz uzakta olanı daha küçük, uzaktaki dairesel bir nesneyi oval görebilir. Bakış, durduğu noktaya bağlı olarak kare bir formu eşkenar dörtgen veya dikdörtgen görebilir (Descartes, 2002: 116 - 121).

4 Logosentrizm, Batı metafiziği içerisinde söz, konuşma, düşünce, mantık merkezli zihni tasarımı ayrıcalıklı bir konum olarak tanımlayan yaklaşımın adıdır. Kavram Türkçeye sözmerkezcilik olarak çevrilmiştir fakat bu çevirinin kavramın anlamını daralttığı düşüncesiyle logosentrizm sözcüğü tercih edilmiştir. 
içerimi ile birlikte güçlü bir şekilde sürdürmektedir. Sosyal yaşamın içinde duyu organlarımızın olanakları ile yol aldığımıza işaret eden Simmel (1969), gözlerin temasının, samimiyet, utanma, anlama, tanıma, şükran belirtme gibi duyguların karşılıklı aktarılmasında, önemli olduğunu vurgulamış, bir anlamda gözün güçlü bir mesaj taşıyıcısı olduğunu ortaya koymuştur. Kişi, içinde bulunduğu etkileşim alanını önemli ölçüde bakarak anlamlandırır ve yönlendirir (Simmel, 1969: 360'dan Aktaran: Ball ve Smith, 1992: 2). Dolayısıyla Simmel'in vurgusunda gözün emsalsiz (unique) bir sosyolojik fonksiyonu olduğu yorumu öne çıkmaktadır (Ball ve Smith 1992: 1-2). Ball da (1998: 140-145) temel argümanını, Simmel'in literatür içinde çok dikkat çekmemiş vurgusu üzerine temellendirmektedir. Gözün görüşünden kameranın görüşüne bir geçiş yapmak adına Ball ve Smith (1992), insan gözünün sosyolojik içeriğini, kameranın hafızası ile birleştirmekte, buradan hareketle teknoloji yardımıyla olanak kazanan görsel kaydı, sosyal bilimlerde bilgi üretme ve saklama potansiyeli olarak önermektedir. Çünkü "sosyal dünya, kısmen [ve kaçınılmaz olarak] görülen dünyadır. Katıımcıların çoğu için görüş (vision), aracı dolayımı ile olanaklı hale gelir" (Ball ve Smith, 1992: 1). Buradan hareketle Ball, özellikle etnografların araştırma sahalarından kesitleri teknoloji yoluya imaj biçiminde kopyalamalarının yöntemsel bir zaruriyet olduğunu savunur. Çünkü yaşantımızın görsel yanının, yazı ile betimlenmesi her zaman verimli ve yeterli olamayabilir. Bütün kültürlerin görsel mevcudiyeti aynı değildir ve tam da bu noktada görsel kayıt, bağlamsal zenginliği ile birlikte kültürlere has birçok farklıı̆ın ve enformasyonun taşıyıcısı olabilecek niteliktedir (Ball, 1998: 135). Görsel kayıt, içerimindeki herşeyi birbiriyle ilişkilendiren, birbirine geçiştiren bir bütün olan bağlamı bir araştırma birimine dönüştürmektedir. Yine de Ball ve Smith (1992: 6) görselliği yazılı araştırma yöntemlerine bir alternatif değil, bir destekleyici olarak önermekte "Biz, insan aklının melekesi olan dilsel ifadeye, deneyimin dilsel bir betimlemeye dönüşmesine muhalefet etmiyoruz. Biz, sadece bunun yanına görselliği de eklemek istiyoruz" demektedir.

Bilgi formu olarak görsellik etrafında dönen tartışmalar antropoloji içinde de yer bulur. Antropoloji ile filmin ilgisini kuran Grimshaw (2001: 7) (antropolog ve etnografik filmci) ve MacDougall (1998: 61-64) (iletişimci ve etnografik filmci), görselliğin teknolojik içeriği nedeniyle, hem endüstri hem eğlence sektörü ile çok kritik bir ilişkisi olduğunu kabul etmekle birlikte, görsel bilgi üretiminin üzerine iki noktada tekrar düşünülmesi gerektiğini savunmaktadırlar: Görsel kayıtlar, modern etnografi içinde yöntembilimsel bir strateji ve teknik olarak, bir bilgi biçimi olarak ve dünyayı bilebilmenin kısmi/özel bir yolu olarak önemlidir. Fakat aslında bu tartışma tarihsel olarak çok daha önce, 19. yüzyılın sonlarından itibaren, antropolojiye görsel kaydın girmesiyle başlamışı̧ı.

\section{Etnografik Film: Tarih ve Tanım}

\subsection{Tarih}

Görsellik modern çağın en önemli icatları ile desteklenmiş, bu dönemde gözün olanakları, teleskop, mikroskop, fotoğraf makinası, sinematograf gibi cihazlarla sürekli geliştirilmiştir. Özellikle 1880 ile I. Dünya Savaşı yılları arası, insanın zamanı ve uzamı deneyimlemesi açısından, yeni teknolojik icatların ve kültürel keşiflerin dönemi olmuştur; bir yanda x-ışınları, sinema, otomobil, kablosuz telgraf, telefon, diğer yanda roman, psikanaliz, kübizm, görelilik teorisi gibi yeni unsurlarla kültürel bilincin de doğrudan şekillendiği yıllardır. Yaşamın ve düşüncenin boyutları değişmektedir (Grimshaw, 2001: 16-18). Modern çağın her anlamda, bilinebilir olanın sınırlarını zorlama cesareti ve cüreti gösterme dönemi olduğu göz önünde bulundurdurulduğunda, görselliğin icadının bilimsel çalışmalar alanına hangi bağlamda dâhil olduğu sorusunu cevaplamak zor değildir: Fotoğraf ve sinematograf cihazları, 19. ve 20. yüzyılların pozitivist karakteristiği dâhilinde, sosyoloji, antropoloji ve psikoloji gibi disiplinlerin çalışmaları içinde sınırlı olarak yer bulmuştur. 
Henley (1998: 42-46) görselliğin sosyal bilimler içindeki pozitivistik kullanımının II. Dünya Savaşı dönemlerine kadar geçerliliğini koruduğunu söylemektedir. Aynı yıllarda, bilim ile pozitivist paradigmanın çakışmasının olağan sonuçlarından biri olarak antropoloji de kendini pozitivizmin kanıt ve ölçülebilirlik kriterlerinde yetkinleştirmeye yönelmiştir; görsel teknoloji araştırma sahasında görsel kanıtlar üretmektedir.

19. yüzyılın sonlarından itibaren birçok bilim insanı, alana fotoğraf ve film kamerasıyla gitmiş̧tir. Felix-Louis Regnault, Baldwin Spencer, Franz Boas, Alfred Cort Haddon ve Rudolf Pöch bunlardan bazılarıdır (el Guindi, 1998: 459). Regnault araştırma sahasında sinematografı Lumiere'lerin ilk gösterimlerini yapmalarından altı ay önce kullanır; 1895 baharında bir Wolof kadınını kap yaparken görüntüler (de Brigard, 1995: 15). Lumier'lerin icadından sadece üç yıl sonra ise, biyoloji alanında çalışmaktan antropolojiye geçen Haddon, kameralar ve fotoğraf makinalarını sırtlamış, altı kişilik çalışma ekibi ile alan çalışmasına çıkmıştır. Kamerayı bir antropoloğun yanından hiç ayırmaması gereken temel araştırma araçlarından biri olarak öneren Haddon, Torres Straits kültürünün yaşam tarzını görüntüler; dans eden adam, ateş yakan adam gibi çekimler yapar (de Brigard, 1995: 16). Regnault ise patolojik anatomi ile ilgilenen bir fizikçi iken antropolojiye yönelmiş ${ }^{5}$, özellikle "karşılaştırmalı etnik psikoloji" çerçevesinde, farklı etnik kültürlerin koşma, zıplama, tırmanma, nesneleri ölçme gibi davranışları üzerine tematik kısa görsel kayıtlar yapmıştır (de Brigard, 1995: 17). 1900'lerin başında, "nesnel gerçeklik gözlenebilirdir" inancı kameranın olanaklarına duyulan güvende somutlaşmış, Regnault sinemayı en nesnel ve zengin belgeyi sağlayan araç olarak görmüştür; sinema teknolojisi ile birlikte sosyal yaşamın bizzat kendisinin kocaman bir laboratuvara dönüştüğünü düşünmüştür (Ruby, 2000: 44). Franz Boas'ın 1894'den itibaren alan çalışmalarında fotoğraf çektiği, 1930 'larda, 70 yaşında hala 16-mm kamera ile kayıtlar yapmayı sürdürdüğü bilinmektedir (Ruby, 2000: 46). Malinowski de katılımcı gözlem yaptığı alan çalışmalarında fotoğraf kaydı yapmış fakat bunları, bilimsel çalışmaların içine dâhil etmemiştir (Clifford, 1986: 13).

Antropoloji disiplini 1920'ler boyunca bilimselleşme uğraşı verir. Kendi bilimsel çalışmalarını ve yöntemlerini turistik ve misyoner kâşiflerin pratiklerinden ayırmaya çalışır. Bu doğrultuda, görselliğin icadı ile birlikte başlayan etnografik filmler, 1920'lerin ortalarında, yavaş yavaş kendi kanonik formlarını bulur. Bu dönemden itibaren, törenler, ritüleller ve el sanatları konularında tek kavramlı filmler ortaya çıkmaya başlar. 1922 antropolojinin ve kameranın birbirlerinden haberdar olmadan yaşadıkları alan deneyimlerinin buluştuğu ilginç bir rastlantının yılı olur: İki ayrı alanda, iki ayrı tarzla çalışan, biri antropolog diğeri coğrafi keşifçi iki ayrı kişi, katıımcı gözleme dayanan çalışmalarının sonuçlarını paylaşır: Malinowski Argonouts of the Western Pacific kitabını Flaherty ise Nanook of the North filmini aynı yıl içinde, 1922'de tamamlar. Bu raslantıya özel bir anlam ve değer atfetmek önemlidir çünkü Flaherty -bir antropolog olmamakla birlikte- ilerde etnografik filminin tarihine, türün en önemli yönetmenlerinden biri olarak kaydedilmektedir (Grimshaw, 2001: $50)$.

1930-1950 arasında, antropoloji içinde Regnault'un takipçisi sayılabilecek iki isim olarak Margareth Mead ve Gregory Bateson görülür. Mead (1995: 10), kamerayı daha rafine ve geniş gözlem olanakları sağlayan özellikleriyle birlikte, doğrudan ve sadece bilimsel çalışmanın bir aracı olarak önerir. Ona göre kamera geçmişi geleceğe taşımanın, kendi kültürümüzde olmayan kültürel nesneleri görebilme olanağı sunmanın aracıdır. İki antropolog, fotoğraflara dayalı

5 Görsel teknolojinin ilk yıllarında kayıtlarıyla öne çıkan Haddon ve Regnault'un farklı alanlardan antropolojiye yönelmiş olması, antropoloji ile görsel kaydın, diğer alanlara göre daha özel bir noktadan -kültürü izleme deneyimi olarak - ilişkilendirildiğine işaret eder. Grimshaw'ın (2001: 7). "antropolojiyi karakterize eden onun ayırt edici görme yoludur", ifadesi bu gerçekliği desteklemektedir. 
Balinese Character'i (1942) savaş yıllarında tamamlar, savaş sonrası da Character Formation in Different Culture Series (1952) adıyla bir filmler dizisini gösterime sunarlar (de Brigard, 1995: 27). Bu iki antropoloğun birlikte yürüttüğü görsel çalışmalar bilimsellik açısından pek de olumlu karşılanmamış, hatta horlanmıştır. Özellikle Mead antropologlar içinde, bilimsel yeterliğinden şüphe duyulan, popüler olanın peşinde koşan bir insan olmakla eleştirilir (Grimshaw, 2001: 87). Bu dönemde antropoloji içinde, Mead ve Bateson'dan başka görsel kayıt yapana rastlanmamasına bakılırsa görsellik yöntemsel bir araç olarak önem görmemektedir. Fakat tek sebep bu değildir; II. Dünya Savaşı başlamıştır. O yıllar, sadece etnografik film ile ilgili çalışmaların değil, birçok bilimsel, sanatsal, ekonomik etkinliğin durduğu yıllar olur.

Savaş sonrasında antropoloji alanındaki çalışmalar duraklama dönemine girmiştir. Bu süreci disiplinin kendi tarihsel sorgulamasını yaptığı, kolonyalist geçmişinin hesabını vermeye başladığı bir aşama olarak değerlendirmek mümkündür. Bu doğrultuda antropoloji teori açısından zayıf ve ağırlıkla fonksiyonalist yöntemselliğin gelişimine hizmet eden bir dönemi arkasında bırakmaya yönelmiştir (Ulin, 2001: 41-45). 1950'lerin sonu ve 1960'lar, sosyal bilimler alanında yeni epistemolojik ve yöntembilimsel tartışmaların gündeme gelmeye başladığı bir dönemdir. Etnometodoloji (H. Garfinkel), sembolik etkileşimcilik (H. Mead), hermeneutik (G. Gadamer) ve fenomenoloji (E. Husserl), bilim ve bilimsellik adına temel noktaları sorunsallaştıran önemli sorular sormaya başlarlar. Epistemolojik temelde sorgulanan "nesnellik", "araştırmacının kültürel ardyöresi", yorumlanmış gerçeklik olarak yeniden kavramlaştırılan "kültür" ve "düşünümsellik" gibi kavramlar, yöntembilim tartışmalarına da önemli açıımlar kazandırmış görünmektedir. Tüm bu gelişmelerin antropoloji disipliniyle mutlaka bağı kurulmalıdır. Zira genel olarak sosyal bilimlerde özel olarak da antropoloji disiplini dâhilinde, yorumsal temelli tartışmaların yeniden değer kazandığı dönemde etnografik film sayısındaki niceliksel artış dikkat çekicidir. Etnografik filmler antropoloji içinde canlı bir tartışmanın konusu olmaya başlar.

Antropolog E. T. Hall The Silent Language (1959) ve The Hidden Dimension (1966) kitaplarında, kültüre özgülüğü sözlü ve sözsüz iletişim kodlarının kullanım ağırlıklarına ve biçimlerine göre ayrıştııır. Gerçekliğin yorumlanmasında kültürel bağlamın belirleyiciliğine işaret edern Hall'e göre kültür yazılabilir olmaktan ziyade görülebilir olarak kavranmalıdır (Ball, 1998: 143). Alanın ilk temel kitaplarından biri bu ortamda çıkar; John Collier Visual Anthropology: Photography as a Research Method (1967)'u yazar, Hall kitaba yazdığı önsözde antropolojide görsel bilgi formuna intiyacın önemini ve aciliyetini vurgular.

Savaş sonrasına gelindiğinde teknik de ilerlemiş, kamera yeni $16 \mathrm{~mm}$ teknolojisi sayesinde hafiflemiştir. Hollywood tarzı stüdyo koşullarından kurtulan kamera, sokağa, gerçek yaşam alanına çıkar. Savaş sonrası sineması gerçekliğin peşindedir: Italya'da Yeni Gerçekçilik (Cesare Zavattini, Vittorio de Sica), Amerika'da Doğrudan Sinema (Richard Leacock, Albert ve David Maysies) ve Fransa'da Cinema Verite (Jean Rouch, Edgar Morin) hareketleri ortaya çıkar (Ruby, 2000: 12). Sinema estetiği içerme kaygısını da taşıyan bu hareketler, gerçek yaşamdan gerçek kayıtlar yapmaya yönelmekte, sosyal yaşamın doğrudan ve gerçekçi bir şekilde izlenmesi ile ilgilenmektedirler. Sinemadaki yeni yönelimler belgesel filmlerde yeni yaklaşımların kapısını açmıştır. Aynı dönemde etnografik film de belgesel konvansiyonlarının rehberliğinde gelişmektedir (Henley, 1998: 45).

1950'de Almanya'da "Bilimsel Film Akademisi" (Institut für den Wissenschaftlichen Film), 1952 senesinde, "Uluslararası Etnografik ve Sosyolojik Film Komitesi" (International Committee on Ethnographic and Sociological Film/CIFE) kurulur (de Brigard, 1995: 28-29). Kurumun başkanı Jean Rouch olur. Rouch'un Batı Afrika'da çalışmalarını sürdürdüğü 1950 ve 1960’lı yıllarda, 
antropolog filmcilerden Karl Heider ve Robert Gardner, Afrika'da sanat ve bilim arasında ilişki kuran bir yaklaşımla filmler yapmaktadırlar (Ruby, 2000: 95-114). 1960'lar ve ardından 1970'ler, etnografik filmin tanınması ve kabul görmesi açılarından yeni kurumsal adımlar getirir. 1966'da Etnografik Film Programı (Program In Ethnographic Film/PIEF) açılır. Devamında Görsel İletişim Antropolojisi Topluluğu (Society for the Anthropology of Visual Communication/ SAVICOM) kurulmuş, 1972'de Görsel Antropoloji Topluluğu (Society for Visual Communication/SVA) olarak yeniden yapılandırımıştır. ${ }^{6} 1960$ 'ların sonundan itibaren alan dergileri de basılmaya başlanır. SVA Visual Anthropology Review'i, Uluslararası Görsel Antropoloji komisyonu ise Visual Anthropology'yi çıkarmaya başlar. 1970'lerde ise alanı tanıtan dergilerde etnografik film üzerine yazılar yer bulmaya başlamıştır (Ruby, 2000: 26).

1970'ler ve sonrasında alandaki önemli etnografik film yönetmenleri bilginin yorumsallığına vurgu yapan yaklaşımların temel argümanlarını ve savlarını alanda sınamaktadır denebilir. Bu kişilerin filmlerinde kamera, yerlinin (social actor, layperson) bakışına görünürlük vermek adına el değiştirir (Worth ve Adair, 1997), düşünümsellik Asch'in The Ax Fight (1971) filminde önemli bir hareket noktasına dönüşür. Film çekimi sırasında, yerlilerle film ekibi arasında kurulan işbirliği (collaboration), yöntemsel olarak araştıran-araştırılan ilişkisini sorgulayan bir deneyime dönüşür.

Bir etnolog olarak 1940'lardan 2004 senesine kadar Nijerya'da etnografik filmler yapan Jean Rouch, Flaherty ile Vertov'un ${ }^{7}$ sinemasını verimli bir şekilde birleştirmekte ve filmlerinde kameraya, girdiği yeri sadece varlı̆̆ıyla değil, ortama müdaheleleriyle de etkileyen aktif bir nitelik yüklemektedir. Provakatif film üsluplarıyla, belgesel film ile kurmaca film arasındaki çizgiyi sorunsallaştırmakta, kendisinin "etnografik kurmaca" ifadesiyle karşılamakta bir sakınca görmediği filmler üretmektedir (Henley, 1998: 46). Rouch'un bu tarzdaki çalışmasını örnekleyen çalışmalarından biri Edgar Morin'le birlikte yaptıkları Chronicle of Summer olur (1961). Kent etnografisinin bilinen görsel örneklerinden sayılan bu filmde Morin ve Rouch, Paris sakinlerine "mutlu musunuz?" diye sorar. Görüşmeciler soruyu, bireyselden toplumsal ve politik olana, olgusaldan duygusala ve kurgusala, nesnellikten öznele kadar genişleyen, geniş bir kişisel bir anlatı ile cevaplarlar.

Bu dönemde, yöntemsellik ve yaratıcııı denemeleri sonucu ortaya çıkan etnografik filmler etrafında bir bilimsellik tartışması ortaya çıkar. Zira bu eserler sosyal bilimlerin bilimsellik kriterlerini sorgulamakta ve eleştirmekte, bunu yaparken yöntembilim tartışmalarının sınırlarını esnetmektedir. Fakat bunun da öncesinde, süreç daha acil bir ihtiyaç olarak tanımlama problemini beraberinde getirmiştir: Etnografik film nedir?

\subsection{Tanım}

6 Etnografik filmin kurumlaşması konusunda Batı dışı bazı ülkelerde de girişimler olmuştur. 1970 senesinde Japonya'da bir arşiv kurulur. Bunun ardından, Jean Rouch'un da katkısıyla Ulusal Film Komitesi'nin kuruluşu gelir. Antropologları, gazetecileri ve sanatçıları bir araya getiren kurum, özellikle etnografik filmin çekimini desteklemek amacında olmuştur (el Guindi, 1998: 465). Öte yandan Batı dışı ülkelerde oturmuş bir belgesel film zemini mevcut olmasına rağmen, etnografik film türünün gelişimi çok önemli bir sosyal ve psikolojik dirençle karşılaşmıştır. Zira film çekme faaliyeti Doğu'da hep seyredilme, filme çekilme olarak, kolonyal dönemlerin ayrılmaz bir parçası olarak deneyimlenmiştir; etnografik film türü de, Doğuda, Batılı-olmayanı izleme/gözleme pratiği biçiminde negatif içeriği ile sabitlenmiş, antropolojinin kolonyal tarihiyle bitiştirilmiştir (el Guindi, 1998: 466-468). Bu nedenle, Mısır, Hindistan vb ülkeler tarafından, etnografik filme yönelen tavır, türün egzotik göndermelerini vurgular niteliktedir.

7 Dziga Vertov 1920'lerde "sine-göz" kuramını geliştirmiş Sovyet sinemacı ve belgeselcidir. Fütürist olarak değerlendirilen Vertov kameranın gözünü, insan gözünden daha yetkin ve daha nesnel bir kayıt cihazı olarak görür. Sine-göz'ün gerçek ve bilimsel imgeler ürettiğini savunur (Vertov, 2007). Vertov'un gerçeklik nosyonu ve montaj kuramı bu çalışmanın çerçevesini aşacak genişlikte olduğundan içeriğe dahil edilmemiştir. 
Alanda yapılan filmlerin tarihi daha eskilere dayanıyor olsa da, "etnografik film diye bir şey var mıdır?" sorusu ilk olarak 1948 senesinde sorulmuş, 1970'li yıllarda film türünün çerçevesini belirleme konusundaki tartışmalarla güncel bir boyut kazanmıştır (Rouch, 1995: 79). Kavramı tanımlama konusunda bir yaklaşım, 1950'lerde, Heider tarafından öne sürülür. Heider, etnografi kavramını insanla ilişkili herşey olarak yorumlar ve buradan hareketle "bütün filmler etnografik filmdir" yaklaşımıyla hem kestirme, hem de karakteristik bir içerik taşımayacak kadar genel bir yaklaşım öne sürer. Ruby, bu duruma bir soru ile yaklaşır: "Peki ama herşey insanlarla ilgili olduğuna göre, etnografik film olmayan nedir o halde?" (Ruby, 1975: 106). Sadece antropologların yaptığı filmler mi etnografik film olarak adlandırılmalıdır? Fakat böyle bir bağlantıda ısrar edilirse, o zaman antropoloji ile bağlantısı olmayan Flaherty, Gardner, Marshall, Asch'ı gibi çok önemli etnografik film yönetmenleri dışarıda kalacaktır (Ruby, 2000: 26-27).

Tanımlama çabası sürer. Etnografik film ile belgesel film arasındaki farklılı̆ın betimlenmesi önem kazanır. Belgeselin tanımlayıcı niteliklerine bakarak, etnografik filmin ayırt edici karakteristikleri ayırt edilmeye çalışılır. Mevcut filmlere bakıldı̆̆ında, etnografik film Batı'ıın Batıı olmayan toplumlarda yürüttüğü bir alan deneyimi ve faaliyeti olarak görünür. Türün tarihsel olarak ortaya çıkışındaki temel motivasyonlardan birisi "kaybolan kültürler"i görüntüleriyle kaydetmek olarak açıklanır. ${ }^{8}$ Nitekim etnografik filmin önderlerinden sayılan Mead ve Bateson, kaybolma riski taşımaksızın büyük bir özgüvenle ilerleyişini sürdüren Batı kültürünün üyeleri olarak, özellikle kaybolan kültürlerin kaydedilmesine yönelmişlerdir (Mead, 1995: 3-10). Etnografik film çeken diğer yönetmenlerin tamamının da Batılı olmayan toplumlar üzerinde yoğunlaşmış olması, Batı ve Batılı olmayanlar ayrımının belirleyiciliğine işaret etmektedir (Hockings, 1995: 510). Bu tarihsel verilerden de hareketle, etnografik filmin kapsamını ve niteliğini ifade etmekte en çok başvurulan sözcük "egzotik" olmuştur (Ruby, 2000; Hockings, 1998; el Guindi, 1998). Şu halde, bu genel olarak benimsenen bir görüş olmasa da etnografik filmlerin, öncelikle, egzotik (tuhaf, yabancı) olan kültürlerin kaydını yapmak özelliğiyle belgeselden ayrıldığını ifade etmek mümkündür.

Etnografik film ile belgesel film ayrımı çerçevesindeki konumlanmalar farklı izleklerde yeniden doğrulanabilir. Ruby (2000), sosyoloji ile antropolojinin alanının ayrım noktalarında değinir. Sosyoloji kendi toplumunu araştıran bir disiplin olarak konumlanmış, Batı için Batılı olan özne sosyolojik çalışmanın konusu olmuştur. Bu doğrultuda ağırlıkla kent içi çalışmalar yürütülmüş, toplumsal yaşamın problemlerine dönük yaklaşım, sorun temelli bir görsel anlatı formu olarak belgesel filmler ortaya çıkmıştır. Etnografik araştırmaların çalışma alanı ise başkalarının kültürü olmuştur, egzotik toplumlar ise etnografik öznelerdir (Ruby, 2000: 27). Böylece antropoloji ile sosyolojinin ayrım noktaları, belgesel ile etnografik filmin ayrıldığı noktaların da altını çizmektedir. Bu ayrımlaştırmaya göre, sosyoloji disiplini ile bağlantılı belgesel film mutlaka bir sosyal sorundan yola çıkar, görsel kaynakları, saptadığı sorunu betimlemekte kullanır. Belgesel film bir tartışma veya doğrudan bir çözüm önerisi içerir, hatta bu öneri mümkünse filmin sonsöz kısmına (bitişine) yerleşir. Antropoloji ile bağ kuran etnografik filmde ise keşfetme ve betimleme vardır. Etnografik film bir sosyal sorunu saptamaya ve çözümünü aramaya yönelmez (Nichols, 1994: 63-94).

Ruby (2000: 167-170)., belgesel filmin etnografik filme en yakın tür olarak görülmüş olması fikrine

8 Türkiye'de, kaybolanın peşine düşme motivasyonu ile hareket eden ve "yarına ne kaldı?" sorusunun izini süren ilk oluşum 1997'de kurulmuş olan Belgesel Sinemacılar Birliği'dir. http://www.bsb.org.tr/index. html (07.04.2014). Etnografik film adlandırmasını benimseyen film örnekleri ise yok denecek kadar azdır. İlk olarak İlkay Nişancı yönetmenliğini yaptığı Bir Yudum Bekleyiş (2006) adlı filmini Türkiye'de Lazlar üzerine ilk etnografik film sözleriyle nitelemiştir. http://arsiv.ntvmsnbc.com/news/375701.asp (07.04.2014). Bunun yanında Işık Sesini Arıyor (Hakan Aytekin, 2001), Sırtlarındaki Hayat (Yeşim Ustaoğlu, 2004) ve Anadolu Düşleri (Gül Muyan, 1998) adlı filmler de etnografik veri içeren belgesel film olarak değerlendirilmiştir (Alan, 2007: 27 - 48). Türkiye'de tür olarak etnografik filmler üzerine tartışmalar hala çok yenidir ve sınırlı ölçüde sürmektedir. 
katılmaz. Bu ilişkilendirmeninin birçok ikilik ortaya çıkardığını öne sürer: Sosyoloji-antropoloji, Batı-Batı olmayan, kent-kır arasına koyulan sert ayrım gibi ikilikler, belgesel film ile etnografik filmlerin ayrım ve benzerliklerine ilişkin görüşleri yerleşik hale getirmiştir. Tüm bu kavramların birbirlerine göre konumlarının yeniden düşünülmesi gerekmektedir. Aksi halde, etnografik film adına olumsuz sonuçları besleyen bu sert ayrımları yaratıcı bir şekilde aşmak pek gerçekçi olmayacaktır. Buradan hareketle Ruby, radikal bir yaklaşımla, etnografik filmi, belgeseli referans alarak değil, kurmaca ve sanat filmlerini referans alarak değerlendirmek gerektiğini söyler. Kurmaca film ve sanat ile ilişkilenme girişiminde iki temel kavramı hatırlatır; bunlar bizzat antropolojinin yorumsallığı içinde önem kazanan "düşünümsellik" ve "anlatı"dır. Anlatı ve düşünümsellik belgeselin pozitivistik metodu nedeniyle ancak sanat filmlerinin ve kurmaca filmlerin yöntemsel unsurlarından olabilmiştir Böylece Ruby (2000: 70) pozitivist epistemolojinin dışarıda bıraktığı "anlatı", "kurmaca" gibi kavramları, etnografik filmler üzerinden sosyal bilimin alanına dâhil etmiştir. Beklendiği üzere, sosyal bilimler alanındaki diyalojik olmayan tartışma ve yaklaşımlara kaynaklık eden ikiliklerden (batı-batı olmayan, ilkel-medeni, antropoloji-sosyoloji, belgesel-etnografik vs.) kurtulmak hamlesi, tartışmayı alanın tanımından yöntembilim sorununa doğru genişletecektir.

\section{Etnografik Film ve Bilimsellik: Sorular ve Cevaplar}

Antropoloji etnografik filmlere karşı uzun yıllar boyunca kayıtsız kalmıştır. Üstelik bunu 1970'lerden itibaren kurumsallaşmış olan görsel antropolojiyi bünyesinde barındırmasına rağmen yapmıştır. Etnografik film yönetmenlerinin bir kısmının antropoloji kökenli dahi olmaması, buna rağmen alan deneyimlerinden hareketle yöntembilimsel tartışmalara dâhil olmaları, üstüne üstlük yaptıkları filmlerin bilimselliğini iddia etmeleri, antropoloji disiplini tarafından bir tür cüretkârlık olarak değerlendirilmiştir, yorumu yapılabilir. Fakat şu da bir gerçektir; etnografik film üretenlerin içinde antropolog olan filmciler de vardır. Ayrıca, antropoloji içindeki bir alt çalışma alanı olarak görsel antropoloji kendi tarihini doğrudan etnografik filmler tarihi ile örtüştürmektedir. Dahası o filmler vardır ve antropolojik çalışmalar olarak birçok izleyiciye ulaşmıştır (Henley, 1998: 49). Dolayısıyla, antropolojinin etnografik filmleri kendisinden uzak tutmasının olanağı yok gibidir (de Brigard, 1995: 13-43; el Guindi, 1998: 459-511).

Etnografik filmlere antropoloji disiplini tarafından yöneltilen temel eleştiriler şu noktalarda ortaya çıkar: Öncelikle, film, video ve fotoğraf gibi dolayımlayıcılar göndergeleriyle her ne kadar belirtisel/ dizgesel (indexical) ilişkide bulunsalar da, nihayetinde onlar gerçekliğin doğrudan kodlanması değil ancak temsilidirler (Henley, 1998: 42). Diğer bir eleştiri ise görsel materyalin fenomenal doğasına ilişkindir. Kodsuz göstergeler olarak imgeler gösterir fakat anlatmaz, denir. Anlatısallık kodlamanın olağan sonucu olarak tanımlanır. Bu bağlamda görsel kaynakların, sosyal bilimcinin betimlemelerini zenginleştirmesi dışında araştırmaya bir katkı sunması beklenmez (Ruby, 1975: 104). Bununla birlikte, görsel içerikler sadece ve basitçe metinsel kodlamayla açıklanabilir içerikler değildir. Görsel birim metindeki sözcük birimden farklı işler, imgeler daha ziyade 'ifadeler' (utterances), yaratıcı anlam birimleri ve hatta teknolojik bir zekâ olarak karşımıza çıkarlar (Crawford ve Turton, 1992: 68-73; Burnett, 2007: 33-34).

Görsel içeriğe dair güvensizlik ve bilimsel açıdan itibarsızlaştırma devam eder. Görsel medyanın kendi iç sınırılıkları nedeniyle bilimsellik kriterleri ile uyumsuz olduğu savunulur. Örneğin kameranın araştırmaya konu olan kültüre girdiği anda, oradaki sosyal hayatın olağan seyrini bozduğu düşünülür. Dahası kamera, onu elinde tutan kişinin ilgi ve merak konularıyla, sempati ve antipati duygularıyla yönlenebilen, sübjektif bir cihazdır, denir (Rollwagen 1990: 287 - 315). Günümüzde bilginin "nesnelliği", araştırmacının da bir sosyo-politik ve kültürel ardyöre sahibi 
olduğu bilgisiyle sorgulanıyor olsa da, bilgi üretim sürecinde nesnellik kolay vazgeçilebilen bir süreç olmamıştır. Sosyal bilimlerin en büyük çabası sağlıklı yollardan bilgi üretebilmenin olanaklarını zayıflatan veya engelleyen tuzaklardan kaçmaya çalışmak olmuştur (Hockings, 1995a). Oysaki makalenin devamında da aktarılacağı üzere, etnografik film alanı kendine önemli ölçüde bu tuzak alanlarından kuvvet devşirmektedir (Hockings, 1995b: 507-529).

Tartışmalarda, doğrudan etnografik filmcilere yönelen en temel ve sert eleştirinin, antropolog Rollwagen'dan geldiği görülür. Rollwagen (1990), film kaydı yapanların gözlem temelli hareket ettiklerini, bu yolla olgusal olanı gerçekliğin önüne koymakta olduklarını ifade etmektedir. Rollwagen'e göre (1990: 287) etnografik filmciler yorumlanmış bilgiye karşı olgusal olanı, etik yaklaşıma karşı emik ${ }^{9}$ yaklaşımı savunmakla birlikte, bu tavırlarını temellendirme konusunda teorik bir yaklaşıma dayanmamaktadırlar. Çünkü yazara göre etnografik filmciler teoriyi yetersiz ve sorunlu bir bakış açısıyla, basitçe veri toplamanın bir yoluymuş gibi değerlendirmektedirler. Dolayısıyla Rollwagen'e göre (1990: 289), etnografik filmciler teoriden ve bir problematikten ziyade, basitçe somut bir "konu"nun (subject matter) olgusallığı bağlamında düşünürler. Nitekim bu düz merak, egzotik olana ilgi ve meraklarını da kısmen açıklayabilir. Diğer bir deyişle, etnografik filmciler, aynen belgeselcilerin yaptığı gibi, gerçekliğin teknolojik cihazların olanaklarıyla kaydedilmesine odaklanırlar fakat gerçekliğin nasıl kavranması gerektiği sorusunu asla sormazlar (Rollwagen, 1990: 290). Üstelik onlar için antropoloji, yöntembilimsel soruların cevaplanmasında da bir başvuru noktası olmamaktadır; bu tür sorularının köklerini antropolojiden ziyade sinemada aramaktadırlar (Rollwagen, 1990: 292). Bütün bunları dile getirdikten sonra Rollwagen (1990: 308). tartışmasının özünü şu şekilde ortaya koyar: Gerilim aslında görsel dolayımlama (visual medium) ile yazılı dolayımlama (textual medium) arasında değil, antropologların geliştirdiği antropolojik bakış ile antropoloji dışından gelen bakış arasında sürmektedir. Dolayısıyla Rollwagen için temel tartışma görselliğin bilimsel çalışmalarda kullanılması ile ilgili değil, görsellik kullanımı konusundaki teorik ve yöntembilimsel yaklaşım yoksunluğu ile ilgilidir. İşaret ettiği yoksunluğu aşmak adına şunu önerir: Öncelikle, etnografik film ifadesindeki etnografik kavramı pratik kullanımında sürekli "egzotik" olanan gönderme yapmakta olan içeriğinden sıyrılmalı, antropoloji disiplininin himayesinde kullanılmalıdır. Mesele görselliğin bilimsel olarak kullanımı ise, etnografik filmler kendilerini antropoloji içinde tanımlamalı ve "antropolojik film" adlandırmasını benimsemelidir. Buna ek olarak, bu filmler mutlaka antropologlar tarafından yapılmalıdır.

Yukardaki eleştirilere etnografik filmciler tarafından cevap niteliğinde açıklamalar gelmiştir. Temel tartışma noktası yazılı ve görsel bilgi üretme formlarının ortaklıkları ve farklılıkları düzleminde sürmüştür. Antropoloji ile etnografik film alanlarını buluşturmaya çalışan, bu nedenle antropolojinin bilimsellik kriterlerini dikkate alarak film yapmaya özen gösteren üç önemli yönetmen vardır: John Marshall, Asen Balikci ve Timothy Asch. Her üç yönetmenin etnografik film tarzları ve çerçeveleri birbirine yakındır. Bu yakınlık onları zaman zaman antropoloji ile ortak çalışmalar içinde olmaya yöneltmiştir. ${ }^{10}$ David MacDougall ise temel tartışmasını yazılı kayıt ile görsel kayıtların ortaklıkları yerine farklılıkları üzerine oturtmuş, etnografik filmlerin biçimine ve içeriğine yönelik eleştirileri, yazılı ile görsel kaydın karşıtığı bağlamında değerlendirmiştir.

Etnografik film yapmaya 1950 'lerde John Marshall ile birlikte yaptığı çalışmalarla başlayan Asch, özellikle 1960’ların sonundan itibaren filmlerini mutlaka bir antropologla fikir alışverişinde

9 Etnografik araştırmalarda yöntemsel olarak etik yaklaşım, araştırmacı ile araştırma nesnesi ile arasında nesnel bir mesafe tanımlar; dışarıdan gözlemi önerir. Emik yaklaşım ise tam tersine bu mesafenin olabildiğince kırıldığı, araştırma nesnesinin kendi sesinin duyulabilmesinin yöntemsel olanaklarını yaratmayı önerir. Bu yaklaşımda nesnellikten ziyade öznellik öne çıkar.

10 Asch ve Balikci 1970'lerde Afganistan'da birlikte çalışmış, The Suns of Hamji Omar (1975) filmini çekmişlerdir. 
bulunarak çekmiş, görüntünün güven sağlamayan, şüphe uyandıran özelliklerini aşmanın yolu olarak "olay-sekans" (event-sequence) anlatımını geliştirmiştir (Henley, 1998: 48)"1. Asch'in filmlerinde dikkatini yönelttiği diğer bir unsur da düşünümselliği alanda ve filmin içeriğinde gerçekleştirebilmenin olanaklarını araştırmak olmuştur. The Ax Fight (1971) filmi içerdiği düşünümsellik unsurlarıyla, özellikle Ruby tarafından beğeniyle karşılanmış, görselliği verimli kullanmanın olanakları açısından bir hareket noktası olarak önerilmiştir.

Asch antropoloji kökenli olmayan bir etnografik film yönetmeni olarak, antropoloji-etnografik film tartışmalarına aktif olarak katılış̧tır. Asch'e göre (1995), (film materyali analiz edilsin veya edilmesin, kurgulansın ya da kurgulanmasın, mevcudiyetiyle bir enformasyon taşır. Asch, görsel kaydın antropoloji içinde temel bir intiyaç olduğunu savunur. Çünkü görsel kayıt yazılı kayıt türünün yeterli olmadığı durumlarda önemli bir bilgi üretme olanağı sunabilmektedir. Zira görsel kayıt, dilden bağımsız koşullarda bilgi üretebilmenin ve aktarabilmenin avantajlarına sahiptir (Rouch, 1995: 79-98). Yazılı betimlemeler çalışma alanlarıyla zamansal ve uzamsal olarak ilişki sürdüremezlerken görsel kayıt bu olanağa sahiptir. Asch bunu Bruce Kopferer'in ilginç bir alan deneyimini aktararak örnekler: Kopferer, Srilanka'da çekmiş olduğu şeytan çıkarma ayetlerini bir yıl sonra tekrar çekmiştir. Eski görüntü ile yenisi karşılaştıııldığında, ayine katılan kişilerin bir önceki seneye göre farklı dizildiği anlaşılmıştır. Böylece törenin senelere yayılan kurallara ve değişikliklere göre uygulandığı anlaşımıştır. Asch'e (1995: 335 - 338) göre bu bilgi, yazılı ve ancak kendi görsel hafızasına dayanarak not tutan sosyal bilimcinin gözlerinden rahatlıkla kaçabilir bir bilgidir.

Aracın doğasından gelen kısıtlılıklar olduğu eleştirisine Asch, alanda her tür teknik aracın bir takım sınırlııklar dayattığını söyleyerek cevap verir. Araştırma sahasında her araç bazı avantajlar sunmanın yanında beraberinde bir takım dezavantajlarıyla vardır. Bu kamera için de geçerlidir. Kameranın saha çalışmasında sağladığı avantajları vurgulayan yönetmene göre, insan gözü görüş açısı içindeki herşeyi aynı anda, eşit dağılan bir dikkatle algılayamaz; algısı ve dikkati, sürekli olarak ilgisini çeken seslere hareketlere durumlara göre yönlenir. Kameranın insan gözü gibi seçici ve eleyici olmaması, mevcut plan çerçeve içindeki herşeyi görmesi ve kaydetmesi, araştırmacı için iki önemli olanak sunar. Bu kayıtlar araşıımacının oradayken dikkatini yöneltememiş olduğu unsurları da içerir. Çerçevenin merkezinde yer alan kişi, durum veya nesne, arka planıyla birlikte, bağlamıyla birlikte kaydedilebilir. Böylece çerçeve içindeki bazı niyet dışı bilgiler, yapılan yorumlamaları tamamlayan, besleyen, çelişkiyi gösteren içerikler olarak önem kazanabilir. Bu Asch'a göre her koşulda daha çok enformasyonla yol almak demektir. Hatta kişi aynı görüntüleri daha sonra defalarca kez izleyebilir, bu yolla kendi algısındaki önyargısal, etnosantrik içerimleri de sınayabilir. Görsel kaydın bir diğer avantajı da feedback olanağının zenginliklerinden faydalanabilmektir. Görüntüler filme konu alan kişilere izletilebilir, bu sırada çekilenlerin içeriği hakkında ek açıklayıcı bilgiler sağlanabilir (Asch, 1995: 349). Nitekim yönetmen Balikci de filmin etnosantrik içerimini tartışma konusu yapar ve araştırmacının her koşulda karşı karşıya olduğu bu tehlikeyi aşmanın bir yolu olarak filmlerinde kullandığı "etnosantrizm testi"ni önerir. Etnosantrizm testi olarak Balikci, Netsilik Eskimos (1965) filmini kendi Batılı öğrencileri ve filme konu olan halk olmak üzere iki ayrı gruba izletmiştir. Böylece film iki tarafın yorumlarının tutarlılık göstermesi ile sınanmıştır (Balikci, 1995: 188).

Asch (1995: 338), filmin gerçekliği inandırıcı bir biçimde nakletmediği eleştirisini kabul eder fakat burada eleştiri hedefinin kamera olmasını doğru bulmaz. Gerçeklik konusundaki şüphenin asıl

11 "Olay-sekans” çekimi, Asch'ın 1950'lerin sonlarından itibaren, John Marshall'in çekimlerini kurguladığı sırada geliştirmeye başladığı bir yöntemdir. Kurgu veya başka yöntemlerle müdahele edilmemiş, tek çerçeveli çekim birimi; bir sekansın bir defada kesintisiz çekilmesi ve böylece kurgu masasında bozulduğu, dönüştürüldüğü şüphelerinin giderilmesi amacı ile düşünülmüş görsel anlatım birimidir. 
nedeni kamera cihazı değil onu kullanan insan faktörüdür. Kamera tek başına çekim yapamaz. Buna ek olarak, Asch, Sol Worth'un, "resimler, bizim çevremizdeki dünyayı yapılandırmamızın bir yoludurlar, o dünyanın resmi değildirler" görüşünü yinelemek yoluyla "gerçeklik"in ne olduğu üzerine yeniden düşünülmesi gerektiğini savunur. "Bize [etnografik filmcilere] yönelen bu şüpheci yaklaşımın bütün etnografik veri türlerine uygulanması gerektiğini düşünüyoruz", der (Asch, 1995: 339) ve bu yolla antropologları ve onların bilimsel üretimlerini de gerçeklik ve temsil tartışmasının konusu haline dönüştürür. Aslında Asch'in bu vurgusu antropoloji için en önemli disipliner tartışmalardan biri ile bağlantılıdır. Antropoloji temsil ve gerçekliğe dair en sert özeleştirel tartışmasını ilk 1986'da Writing Culture kitabıyla görünür kılmıştır. ${ }^{12}$

Konu ile ilgili tartışmalara katılan bir diğer isim David MacDougall'dir. Etnografik filmi ve antropolojiyi "yazı merkezli" ve "görüntü merkezli" kayıt bağlamlarında karşılaştıran MacDougall, görselliğin yazılı sosyal bilim formundan tamamen bağımsız türde bir bilgi formu olduğunu savunur. Ona göre yazılı ve görsel içerikler arasında bir uzlaşı ve buluşma noktası aramak tek yol olmadığı gibi şart da değildir. Görselliğin kendi içinde, kendi özgül nitelikleriyle değerlendirilmesi gerektiği yönündeki yaklaşımını, üvey evlat gibi görülen etnografik filmden farklı olarak antropolojinin içinde kendine zor da olsa yer bulabilmiş olan "görsel antropoloji"ye de önerir. Görsel antropoloji, kendisini yazılı antropolojinin terimleri ve konvansiyonları ile değil, onun dışında ve ona alternatif olarak, ilgili fenomeni bilmenin bir başka yolu olarak yeniden tanımlamalıdır. Diğer bir deyişle, görsel antropoloji klasik antropolojiye benzemeye çalışmak yerine, kendi karakteristik farklarını devreye sokmalıdır. Tartışma ortamına aktif olarak katılııs olan MacDougall (1998: 63), kendi önerisi doğrultusunda sözcük-ve-cümle-temelli antropolojiye karşı imaj-ve-sekans-temelli antropolojik düşünceyi tercih ettiğini vurgular.

MacDougall (1995), görselliğe ve etnografik film türüne yönelik eleştirileri iki noktadan karşılar. Gerçeklik tartışmalarına Edgar Morin'den aktardığı bir alıntıyla dâhil olur: "gerçek, kazanılacak, ulaşılacak 'kutsal kâse' değildir. O bir ayar düğmesidir; gözleyen ile gözlenen, bilim ile gerçeklik arasında sürekli hareket eder", diyerek görselliğe yönelen gerçeklik eksenli eleştirilere muhalefet eder (MacDougall, 1995: 115). Buradan hareketle kameranın içinde bulunduğu ortamı değiştirdiğine işaret eden yorumlara, aynı doğrultuda kameranın ortamda görünmez kılınması yönündeki öneri ve çabalara, gerçekliğin asıl "ortamda mevcut birşey yok sayıldığında" zarar göreceğini vurgulayarak cevap verir. Çünkü oradaki gerçeklik kamerayı da içine alan haliyle bir bütün içinde varlık bulur. Yani kamera bağlama dâhildir. Şu halde kameralı bir ortam bozulmuş bir gerçeklik değil, yeni bir bağlamda bir başka gerçekliktir; ortamla ilişki ve etkileşim kurar. Böylece MacDougall bir yandan kameranın varolan bir gerçekliği bozduğu eleştirisine cevap verirken, bir yandan da kamerayı saklayarak kayıt yapmayı öneren "gözlemleyici sinema"13 yaklaşımının

12 Writing Culture (1986) adlı kitapta James Clifford ve George Marcus antropoloji disiplini içindeki eleştirel perspektifi ve tartışmaları konu alan metinleri derlerler. Tüm sosyal bilimler alanında geniş tartışmalara yol açan kitap öncelikle Antropoloji disiplininin kolonyal mirasın yükü ile hesaplaşmasını ve bunun ürettiği tartışmaları kayda alır. Kolonyal geçmiş alandaki bilgi üretim süreçlerini belirlemiștir. Antropolojinin onyıllar boyunca tüm "etnografik öteki”leri, yanlış bir mekansallık, zamansallık, tarihsellik, dilsellik ve bağlamsallık içinde temsil ettiği, dolayısıyla hem yanlış hem de eşitsiz bilgi üretimine meydan verdiği, bugün sadece yorum değil bir tespittir artık. Bu tespit ile birlikte bilim-gerçeklik-bilgi ilişkisi şüpheli bir hale gelmiş ve artık "temsil" kavramı ile birlikte düşünülmeye başlanmıştır. Antropoloji içinde bu tartışma bilimsellik, güç ilişkileri ve temsil dilini elinde tutan otoriteler bağlamında genişlemiş, bu doğrultuda "temsil krizi" (crisis of representation) tartışmanın şemsiye kavramlaştırmalarından biri olarak dikkat çekmiştir.

13 Gözlemleyici sinema (observational cinema) yaklaşımı etnografik filmcinin kaydettıği kültürel topluluğun pratiklerini etkilemeyecek bir mesafeye yerleşmesini, film kamerasının sahada mümkün olduğunca görünmezleşmesini önerir (Young, 1995: 99 - 113). MacDougall kameranın ortamd amevcut olduğu halde "yokmuş gibi davranmasını" hem filmin nesnellik iddiası açısından, hem etik açıdan problemli bulur. Bu yolla iddia edilen nesnelliğin doğru olmadığı gibi, film yönetmenini de çektiği filmin sorumluluğunu taşıma yükünden kurtardığını, dolayısıyla bu yaklaşımın bir samimiyetsizlik ve sorumsuzluk ürettiğini savunur (1995: 115 - 132). 
görüşlerini eleştirir. Ortamda yok gibi davranarak kayıt yapmak kişiyi evrensel hakikatin ajanları gibi konumlandırmaktadır ki bu, alanda kalem kağıtıyla bulunan antropolog için de geçerlidir. Ayrıca MacDougall (1995: 119-120) kameranın yerli ile iletişiminin, yerlinin bakış açısının filme yansıması gerektiği konusunda ısrar eder. MacDougall'in bu görüşü, belgesel kökenli Bill Nichols (1994) ve Fatimah Tony Roby (1996) adlı yazar ve yönetmenler tarafından da desteklenir. Özellikle Nichols etnografik film çekim sürecinin her türlü alan deneyimini, antropolojinin yazı merkezli pozitivistik duruşuna karşı alternatif olarak önermiştir. Buna karşın Ruby (2000: 29-32) ise Nichols'u antropoloji içindeki teorik ve yöntembilimsel gelişmeleri takip etmemekle, antropolojiye güncel ile bağlantısı olmayan eleştiriler yöneltmekle eleştirmiştir.

Tartışmaya dâhil olan bir kişi Paul Hockings'dir. Antropoloji disiplini ile etnografik film arasında bir uzlaşı noktası arayan Hockings (1995: 526), tartışmanın bilimsellik kriterlerine sıkışmasını eleştirmiş, etnografik filmleri bilimin otoritesinden kurtarmayı savunmuştur. Ona göre, yazılı ve görsel kayıt karşı karşıya getirilmemeli, kendi özgüllükleri dâhilinde değerlendirilmelidir. Zira ikisinin çalışma yöntemi farklıdır. Antropolog kaydettiklerinin bütününü dikkate alıp sentez yaparak bir yoruma ulaşırken, soyutlamalar ve kavramlarla yol alırken, film çeken kişi doğrudan çektiği parçalı görüntülerle çalışır. Etnografik filmcilerin çalışma tarzı fenomenolojiktir. Onların yöntemi ne mantığın tümdengelimli yöntemidir, ne de doğa bilimlerinin empirik yöntemine benzer. Etnografik filmcinin tarzı, antropoloğun deneyimlemesi mümkün olmayan bir yaklaşım olarak özeldir.

Hockings (1995: 518) tartışmadaki temel eleştiri odaklarından bir diğeri olan nesnellik/öznellik kriterlerinin yerine ise dürüstlük ve samimiyeti koyar ve alanda etnografik filmcilerin daha dürüst olduğunu iddia eder. Etnografik filmci içine girdiği kültürde, toplumda bir yabancı olduğunu saklamaz (katılımcı kamerayı kastetmektedir). Oysaki elinde not defteri ve kalemiyle alanda gezinen antropoloğun tam olarak ne yaptığı, defterine neler not aldığı, kültürün aktörleri için bir bilinmezdir Film, nesnelliği daha kolay sınanabilir bir ürün olmasına rağmen güvenirlik sağlama konusunda problem yaşamaktan kurtulamaz diyen Hockings bunu şuna bağlar: Etnografik film etiktir ama emik bir yaklaşımla yazmaya çalışır. Etik format sahibiyken emik yolla betimlemeler yapmaya çalıştığı için bu onun güvenirliğini sarsar. Hockings (1995: 519) için birçok antropoloğun bu filmleri yok saymaya kalkışmasının nedeni budur.

Jay Ruby yaklaşık 40 yıldır "etnografik film" üzerinde bilimsel çalışmalar ve sosyal faaliyetler yürütmekte olan bir antropologdur. Ruby de (2000), Rollwagen gibi etnografik film çalışmaları ile antropolojiyi, antropoloji disiplininin içinde buluşturmaya çalışır ve "etnografik film" kavramı yerine "Görsel Illetişim Antropolojisi" kavramını kullanmayı önerir. Öte yandan antropolojinin yöntembilimsel perspektifine dönük filmciler tarafından gelen eleştirileri de cevaplar, alanın aslında 1960 'lardan itibaren yorumsal ve bir bilgi edinme yolu olarak görsel tekniklere kapısını aralamış olduğunu hatırlatır. Dahası, özellikle 1980 'lerin ortalarından itibaren antropoloji, kendi pozitivist yaklaşımını ve kolonyalizm ile disipliner bağlarını özeleştiri vererek kabullenmiş ve daha demokratik bir yöntembilimsel perspektifin geliştirilmesi konusunda düşünümsel açılımları benimsemeye hazır bir tutum içine girmiştir (Ruby, 2000: 4). Ruby, bir yandan antropoloji disiplini ile ilgili bu olumlu değerlendirmelerini aktarırken, aynı zamanda antropologlara dönük eleştirilerini de ifade etmiştir. Onların etnografik filmlere uzun süre kayıtsız kaldığını söylemiş, bu nedenle görsel teknoloji konusunda da ısrarla bilgisiz kaldıklarını vurgulamıştır. Zira görsel olanaklar sistemli bir şekilde kullanılabilmeleri halinde antropolojinin temel araçlarından biri olarak çok önemlidir. Ruby (1975: 104-111), "etnografik bir film, filmik bir etnografi mi demektir?" diye sorarak etnografik filmde "görsel" ve "filmik" olanın karakteristik, özgül ve yaratıcı yerine işaret eder. 
Etnografik filmcilerin kuramsal bir altyapıdan ve perspektiften yoksun olduğu konusunda Rollwagen'e katılan Ruby'nin de sınırları vardır. Etnografik filmcilerin alan deneyimlerinde ortaya çıkan ve bilgi üretimini demokratize etmek adına "yerlinin/öznenin kendi filmini çekmesi" yöntemini öneren yaklaşımlar Ruby tarafından kabul edilebilir değildir. Zira Ruby de, aynen Rollwagen gibi, teori ile temellenen bir yaklaşım içinde hareket etmek gerektiğine inanmaktadır. Ona göre teori sosyal bilim için vazgeçilemez bir disiplin donanımıdır ve ancak eğitimle gelişir. Dolayısıyla, ona göre, kültürün üyesi bir kişinin kendisini filme alırken bir teori dahilinde hareket edemeyeceği açıktır. Yerli bambaşka motivasyonlarla çekim yapabilir, nesnel olmak sorunsalı bir yana, açıkça faydacı yönelimlere dahi girebilir. Çekim sürecini ve içeriğini kendi amaç ve motivasyonları doğrultusunda yönlendirebilir (Ruby, 2000: 30-32).

Ruby (2000: 152-153), kültürün yorumsallığını ve performatifliğini vurgulayan Geertz, Goffman ve Turner gibi teorisyenlerle, Flaherty, Asch, Lomax, Rouch, MacDougall gibi etnografik film yönetmenlerini buluşturmada yeni bir kuramsal ve yöntembilimsel buluşma noktası araştırır. Kendisi bu yeniden tartışma sürecini, düşünümsel film ile düşünümsel antropoloji arasında bir ilişki arayışı olarak formüle eder. Belgeselin, belgeleme, kanıtlama gibi ihtiyaçları meşrulaştıran pozitivist dayanaklarından uzaklaşarak düşünmeyi, etnografik filmi daha ziyade sanat, kurmaca film, yorumsallık, anlatısallık ve kültürün performatifliği gibi kavramlar etrafında yeniden tanımlamayı önermekte, böylece etnografik filmi antropolojinin içine çekmekte ve filmin kavramsal dominasyonundan kurtarmaktadır. Performans kavramını bu tartışmanın içine Ruby sokmuştur fakat kültürün performatifliği ondan da önce, yönetmen Rouch'un ve Asch'in etnografik filmlerinde, ayrıca Lomax'ın etnomüzikoloji çalışmalarında temel temalardan olmuştur. Ruby'e göre performatiflik, bir kültürün görülebilir/görselleştirilebilir yanlarına göndermede bulunmanın yanında, kişinin yargılayıcı/kendi kültürel ardyöresinin farkına varmaksızın bakmasını da kısmen giderebilme potansiyeli taşır. İnsan davranışlarına, kültürel olarak inşa edilmiş performanslar dizisi olarak bakabilmek, araştırmacıya kültürü yargılayıcı olmayan, üretken bir içerikle izleyebilme olanağı sağlayacaktır (Ruby, 2000: 253). Ruby, anlatı, düşünümsellik, performatiflik kavramlarını şu sorunun cevabını bulmak adına, etnografik film alanı içinde buluşturur: "Kültürü görebilir misiniz ve onun filmlerini yapabilir misiniz?" (Ruby, 2000: 251). Bu sosyal bilimlerin geneline doğru genleşen bir soru olarak sorulamaz mı? Görsel düşünce ve görsel iletişim, sosyal bilimler için yöntembilimsel bir soru olamaz mı?

\section{Sonuç: Etnografik Filmden Görsel Düșünceye}

Bu çalışmada, etnografik filmlerden hareketle, görselliğin sosyal bilimlerdeki yerini sorgulamaya açan tartışmalar konu edilmiştir. Bu tartışmalar da göstermiştir ki, antropolojinin içinde kabul ile red arasında bir yerde gelişmiş bir kanon olarak etnografik filmler, görselliğin basitçe bilgi ve analiz nesnesi değil, aynı zamanda bilgi formu olarak da değerlendirilmesine olanak sağlamıştır. Filmsel anlatımın niteliği, kapasitesi ve bilimselliği etrafındaki tartışmaların epistemolojik ve yöntembilimsel açıdan ürettiği yeni soru ve sorunlar tüm sosyal bilimler alanına yayılmıştır.

Etnografik filmler ile antropoloji arasındaki bu hararetli tartışmayı hatırlamak önemlidir. Çünkü aynı sorular, gerçeklik, temsil ve söylem, öznellik ve nesnellik, araştıran ve araştırılan arasındaki ilişki, bilginin demokratikleşmesi ve aktivist medya, gibi geniş bağlamlara yayılmakta, bugünün de soruları olmayı sürdürmektedir. Üstelik günümüzde tartışmanın muhatapları, tüm sosyal bilimler ve güzel sanatlar alanı olarak genişlemiştir. Buna ek olarak, özellikle dijital teknolojilerle birlikte yeni imge türleri ve yeni imge rejimleri ortaya çıkmış, bu doğrultuda görsel bilginin formları da kendi içinde çeşitlenmiştir. Dolayısıyla imgelerin çokluğu ve çoğulluğu ile çevrili bir dünyada, imgelerin gücü, gerçekliği, anlamı ve görsel bilgi formu üzerine düşünmek için bugün daha çok bileşenli yapıda, sürekli güncellenen bir sosyo-kültürel ve politik bağlam söz konusudur. 
Kavramsal düşünce yelpazesi imgelerin ürettiği tartışmalarla genişlemektedir.

Antropoloji disiplini içindeki tartışmalardan yola çıkan çalışma, konu ile ilgili güncel bir çalışma alanına işaret ederek sonlanacaktır. Yazınsal ile görsel bilgi arasındaki farkı, yeni üretken sorgulamalar ve hatta yöntemsel bakış önerileriyle zenginleştiren bu önemli alan iletişim çalışmalarıdır. Zira görsellik iletişim çalışmalarının da en temel araştırma alanlarından biridir. Hem sosyal bilimler hem de doğa bilimleri ile bağ kurabilecek ölçüde disiplinlerarası genişliğe sahip bu alanda, görsellik, temsil ve gerçeklik, belge-kanıt niteliği ve söylemsellik gücü bağlamlarında asla tüketilemeyen bir sorgu alanı mevcuttur. Dolayısıyla günümüzde etnografik film etrafında yürütülen ilk tartışmaları zorlayarak aşan birçok yeni gelişme yaşanmakta, imgenin bilimselliğine ve bilgi formu olarak karakteristik özelliklerine dönük sorgular genişlemektedir. Günümüzde görsellik ve toplumsal yaşam arasındaki irtibat, resimsel olandan grafik olana, fotoğraftan postfotoğrafik imge tartışmalarına, aynadan kitle medyasına, sanatsal imgeden popüler tüketim imgelerine, tarihin imgesinden belleğin imgesine, dijital teknoloji imgelerinden teknolojikleştikçe imgeselleşen ve logosantrik sınırı aşan düşünüm ve tahayyül pratiklerine kadar çoklaşmakta ve çoğullaşmaktadır. Görsellik bağlamında dile getirilen bu geniş yelpaze, bilginin formunu ve niteliğini de kaçınılmaz olarak değiştirmektedir; görsel içerikler gündelik yaşamın her alanına dahil olan boyutlarıyla, yukarıda aktarılan tartışmanın geliştirilmesini ve güncelleştirilmesini dayatmaktadır. Zira görsel olan, pozitivistik sorgu ile sınanmanın da ötesine geçmekte ve artık kendi tanımını ve kendi bilimini arzu etmektedir.

Sonuç olarak, etnografik filmler örneği özelinde yöntembilim üzerine tarihsel bir tartışmayı hatıllamak ve görselliğin bilgi ve bilimsellik potansiyellerine dönük sorgulamaları yeni bileşenlerle genişletmek, genelde sosyal bilimler özelde ise iletişim çalışmaları açısından temel önemdedir. Nitekim bu makale şimdilik soruyu hatırlatmakla yetinmiştir, sorunun cevaplarına ilişkin akademik tartışma bundan sonraki çalışmaların konusu olacaktır.

\section{Kaynakça}

Alan, G. Aygül Ernek (2007). "Etnografik Veri İ̧̧eren Belgesel Filmlere Türkiye'den Üç Örnek." İstanbul Üniversitesi İletişim Fakültesi Dergisi. No. 29: 27-48.

Asch, Timoty ve Asch, Patsy (1995). "Film in Ethnographic Research." Principles of Visual Anthropology. Paul Hockings (der.) içinde. New York: Mounton de Gruyter: 335-360.

Balikci, A. (1995). "Reconstructing Cultures on Film." Principles of Visual Anthropology. Paul Hockings (der.) içinde. New York: Mounton de Gruyter: 181-191.

Ball, Michael. S. ve Smith, Gregory W. H. (1992). Analyzing Visual Data. Newbury Park, CA: Sage.

Ball, M. S. (1998). "Remarks on Visual Competence as an Integral Part of Ethnographic Fieldwork Practice: The Visual Availibility of Culture." Image-based Research: A Sourcebook of Qualitative Researchers. John Prosser (der.) içinde. London: Falmer: 131-147.

Burnett, Ron (2007). İmgeler Nasıl Düşünür. Güçsal Pusar (çev.). İstanbul: Metis.

Clifford, James (1986). "Introduction: Partial Truths." Writing Culture: The Poetics and Politics of Ethnography. James Clifford, George E. Marcus (der.) içinde. Berkeley: University of California: 1-26. 
Clifford, James ve Marcus, George (der.) (1986). Writing Culture: The Poetics and Politics of Ethnography. London, Berkley: University of California.

Crary, Jonathan (2004). Gözlemcinin Teknikleri. İstanbul: Metis.

Crawford, Peter lan ve Turton, David (1992). "Film as Discourse: The Invention of Anthropological Realities." Film as Ethnography. Peter lan Crawford and David Turton (der.) içinde. Manchester: Manchester University: 66-82.

de Brigard, Emilie (1995). "The History of Ethnographic Film." Principles of Visual Anthropology. Paul Hockings (der.) içinde. New York: Mounton de Gruyter: 13-43.

Descartes, Rene (2002). "Optics.” Visual Culture Reader. Nicholas Mirzoeff (der.) içinde. New York: Routledge: $116-121$.

el Guindi, Fadwa (1998). "From Pictorializing to Visual Anthropology." Handbook of Methods in Cultural Anthropology. H. Russel Bernard (der.), içinde. Walnut Creek, Calif: Altamira Press: 459 - 511.

Grimshaw, Anna (2001). The Ethnographers Eye: Ways of Seeing in Modern Anthropology. Cambridge: Cambridge University.

Henley, Paul (1998). "Filmmaking and Ethnographic Research." Image-based Research: A Sourcebook of Qualitative Researchers. John Prosser (der.) içinde. London: Falmer: 42-59.

Hockings, Paul (der.) (1995). Principles of Visual Anthropology. New York: Mounton de Gruyter.

Hockings, Paul (1995). "Conclusion: Ethnographic Film and Anthropological Theory." Principles of Visual Anthropology. Paul Hockings (der.) içinde. New York: Mounton de Gruyter: 507-529.

Jay, Martin (1994). Downcast Eyes: Denigration of Vision in Twentieth-Century French Thought. London: University of California Press.

MacDougall, David (1995). "Beyond Observational Cinema." Principles of Visual Anthropology. Paul Hockings (der.) içinde. New York: Mounton de Gruyter: 115 - 132.

MacDougall, David (1998). "Visual Anthropology and the Ways of Knowing." Transcultural Cinema. Lucien Taylor (der.) içinde. New Jersey: Princeton University Press: 61-92.

Mead, Margareth (1995). "Visual Anthropology in a Discipline of Words." Principles of Visual Anthropology. Paul Hockings (der.) içinde. New York: Mounton de Gruyter: 3-10.

Mirzoeff, Nicholas (2002). "What is Visual Culture?" Visual Culture Reader. Nicholas Mirzoeff (der.) içinde. New York: Routledge: 3-23.

Mitchell, W.J.T. (1995). Picture Theory: Essays on Verbal and Visual Representation. Chicago: University of Chicago Press.

Nichols, Bill (1994). Blurred boundaries: Questions of Meaning in Contemporary Culture. Bloomington: Indiana 
University Press.

Panofsky, Erwin (2012). İkonoloji Araştırmaları: Rönesans Sanatında İnsancıl Temalar. Orhan Düz (çev.).. İstanbul: Pinhan.

Roby, Fatimah Tobing (1996). The Third Eye: Race, Cinema and Ethnographic Spectacle. Durham: Duke University.

Rollwagen, Jack R. (1990). “The Role of Anthropological Theory in 'Ethnographic' Filmmaking.” Anthropological Filmmaking. Jack R. Rollwagen (der.) içinde. NewYork: Harwood Academic Publishers: 287-315.

Rouch, Jean (1995). "The Camera and Man.” Principles of Visual Anthropology. Paul Hockings (der.) içinde. New York: Mounton de Gruyter: 79-98.

Ruby, Jay (1975). "Is an Ethnographic Film a Filmic Ethnography?". Studies in the Anthropology of Visual Communication II (2): 104-111.

Ruby, Jay (2000). Picturing Culture: Explorations of Film and Anthropology. Chicago: University of Chicago.

Ulin, Robert (2001). Understanding Culture: Perspectives in Anthropology and Social Theory. Oxford: Blackwell. Vertov, Dziga (2007). Sine-Göz. Ahmet Ergenç (çev.). İstanbul: Agora.

Worth, Sol ve Adair, John (1997). Through Navajo Eyes: An Exploration in Film Communication and Anthropology. New Mexico: New Mexico Press.

Young, Colin (1995). "Observational Cinema.” Principles of Visual Anthropology. Paul Hockings (der.) içinde. New York: Mounton de Gruyter: 99 - 113. 